\title{
Hypoxanthine as a Measurement of Hypoxia
}

\author{
OLA DIDRIK SAUGSTAD ${ }^{(21)}$ \\ Perinatal Research Unit, University Hospital, Uppsala, Sweden
}

\section{Extract}

The hypoxanthine concentration in plasma was found to be a sensitive parameter of hypoxia of the fetus and the newborn infant.

The plasma level of hypoxanthine in the umbilical cord in 29 newborn infants with normal delivery varied between 0 and $11.0 \mu \mathrm{mol} / \mathrm{liter}$ with a mean of 5.8 $\mu \mathrm{mol} / \mathrm{liter}$, SD 3.0 $\mu \mathrm{mol} /$ liter.

Compared with this reference group the hypoxanthine concentration in plasma of the umbilical cord in 10 newborn infants with clinical signs of intrauterine hypoxia during labor was found to be significantly higher, with a range of $11.0-61.5 \mu \mathrm{mol} / \mathrm{liter}$, with a mean of $25.0 \mu \mathrm{mol} / \mathrm{liter}$, SD 18.0 $\mu \mathrm{mol} /$ liter.

The plasma level of hypoxanthine in two premature babies developing an idiopatic respiratory distress syndrome was monitored. The metabolite was found to be considerably increased, in one of them more than $24 \mathrm{hr}$ after a period of hypoxia necessitating artificial ventilation.

The hypoxanthine level in plasma of umbilical arterial blood was followed about $2 \mathrm{hr}$ postpartum in three newborn infants with clinical signs of intrauterine hypoxia. The decrease of the plasma concentration of the metabolite seemed to be with a constant velocity, as it was about $10 \mu \mathrm{mol} / \mathrm{liter} / \mathrm{hr}$ in these cases.

A new method was used for the determination of hypoxanthine in plasma, based on the principle that $\mathrm{P}_{\mathrm{O}_{2}}$ decreased when hypoxanthine is oxidized to uric acid.

\section{Speculation}

These preliminary results indicate that the hypoxanthine concentration in plasma is a sensitive parameter of hypoxia. It is expected that this metabolite will express the degree of hypoxia quantitatively and regardless of the etiology of the hypoxia. The excretion of hypoxanthine and other purine metabolites in urine might also have diagnostic value.

It has been known for more than 40 years that the concentration of uric acid in plasma and its excretion in the urine is increased during anaerobic conditions (12). Berne (2) found that there was an increased liberation of inosine and hypoxanthine into the coronary circulation when the myocardium of cat and dog was ischemic. Crowell et al. (6) showed that in hemorrhagic shock there was an increased catabolism of high energy purines to uric acid. During the past years a series of other papers have confirmed these results $(1,5,13)$.

Figure 1 describes schematically the purine catabolism from AMP (modified from Cantarow and Schepartz (4)). As oxygen is needed for the transformation of hypoxanthine into uric acid, the reaction will probably be slowed down when the availability of oxygen is reduced. Hence we can imagine that during hypoxia there will be accumulation of hypoxanthine.

Lack of oxygen will of course slow down the oxidative phosphorylation, and the concentration of AMP will increase. From the chemical equilibria it can be deduced that an increased AMP concentration, as in hypoxia, will also lead to an increased degradation of AMP, and consequently an increased production of inter alia hypoxanthine.

It is also known that xanthine oxidase is inhibited during hypoxia (3). This too will in turn be followed by a slowing down of hypoxanthine transformation. These three factors will lead to an increased level of hypoxanthine in plasma during hypoxia.

The purpose of this work was to test whether hypoxanthine could be a useful parameter of hypoxia.

\section{METHODS}

The methods available previously for determination of hypoxanthine were either time consuming, or needed too large volumes of blood for perinatal studies, or both (9). A method was therefore developed that fulfills the requirements of such studies (16).

After addition of xanthine oxidase to plasma, hypoxanthine will be transformed into uric acid and oxygen will be consumed (Fig. 1). By measuring the decrease in $\mathrm{P}_{\mathrm{O}_{2}}$ with a Clark electrode, the hypoxanthine concentration is calculated by the use of Henry's law:

$$
\mathrm{dPO}_{2}=\mathrm{K} \cdot \mathrm{d}\left(\mathrm{O}_{2}\right)=\mathrm{K} \cdot(\mathrm{Hx})
$$

$\mathrm{dPO}_{2}$ is the decrease in $\mathrm{P}_{\mathrm{O}_{2}}$ during the chemical reaction and $\mathrm{d}\left(\mathrm{O}_{2}\right)$ is the decrease of the concentration of oxygen equal to the concentration of transformed hypoxanthine $(\mathrm{Hx})$ to urate.

In 1 liter plasma at $38^{\circ}$ and $760 \mathrm{~mm} \mathrm{Hg}$ oxygen, $24 \mathrm{ml}$ oxygen is dissolved $(7,14)$. The volume is corrected to standard temperature and pressure. It then follows that the constant, $K$, is

$$
\begin{aligned}
& \frac{760}{24 \cdot 1.429 \cdot 10^{3} / 32} \frac{\mathrm{mm} \mathrm{Hg}}{\mu \mathrm{mol} / \mathrm{liter}} \\
& =0.71 \mathrm{~mm} \mathrm{Hg} / \mu \mathrm{mol} / \mathrm{liter} \\
& (\mathrm{Hx})=1.4 \cdot \mathrm{dPO}_{2} \mu \mathrm{mol} / \text { liter }
\end{aligned}
$$

in which 1.429 is the specific density (milligrams per milliliter) of oxygen at $0^{\circ}$ and $760 \mathrm{~mm} \mathrm{Hg} \mathrm{(8),} \mathrm{and} 32$ is the molecular weight of oxygen.

The method requires $150 \mu \mathrm{l}$ plasma and concentrations down to about $5 \mu \mathrm{mol} /$ liter may be detected. The time of measurement is $5 \mathrm{~min}$. The precision is calculated to about $\pm 3.0 \mu \mathrm{mol} /$ liter in the measurement of concentration in the range of $0-50 \mu \mathrm{mol} /$ liter.

The enzyme is not specific. It also catalyzes the oxidation of aldehydes and some other purines (3). Recovery experiments and addition of aldehydes and purines to plasma show, however, that this method is highly specific during physiologic conditions. Drugs catabolized to aldehydes might interfere 
with hypoxanthine determination. This has not yet been investigated.

A Radiometer $\mathrm{P}_{\mathrm{O}_{2}}$ electrode E 5046/0 was used with a $\mathrm{pH}$ meter 27 (17).

\section{RESULTS}

The hypoxanthine concentration in the plasma of the umbilical cord of 29 newborn infants with normal delivery ranged from $0-11 \mu \mathrm{mol} /$ liter with a mean of $5.8 \mu \mathrm{mol} / \mathrm{liter}$, SD $3.0 \mu \mathrm{mol} / \mathrm{liter}$. No efforts were made to separate arterial and venous umbilical cord blood, presupposing small venous arterial differences.

In 12 infants with clinical signs of intrauterine hypoxia the hypoxanthine level in the umbilical cord plasma was increased in 10 infants (Fig. 2) compared with the reference group. The hypoxanthine level of this group ranged from $6.0-61.5$ $\mu \mathrm{mol} /$ liter with a mean of $25.0 \mu \mathrm{mol} / \mathrm{liter}$ and SD 18.0 $\mu \mathrm{mol} /$ liter. The difference betwee $\ldots$ this group and the reference group is significant $(P<0.01)$ according to the Wilcoxon test.

Hypoxia was defined according to one or more of the following criteria: Apgar score $(1 \mathrm{~min}) 6$ or less, intrauterine bradycardia (fetal heart rate $<100 / \mathrm{min}$ ), or meconium-stained amniotic fluid.

Two infants with diagnosed intrauterine hypoxia according to these criteria had normal hypoxanthine levels (Table 1). In case 7 , Table 1, hypoxia was diagnosed because of meconiumstained amniotic fluid, but continuous fetal heart monitoring during the last $2 \mathrm{hr}$ before delivery was normal. If there was a period of hypoxia it is therefore likely that this took place more than 2 hr before delivery. Case 9, Table 1, was an infant with a breech delivery without any complication until the last
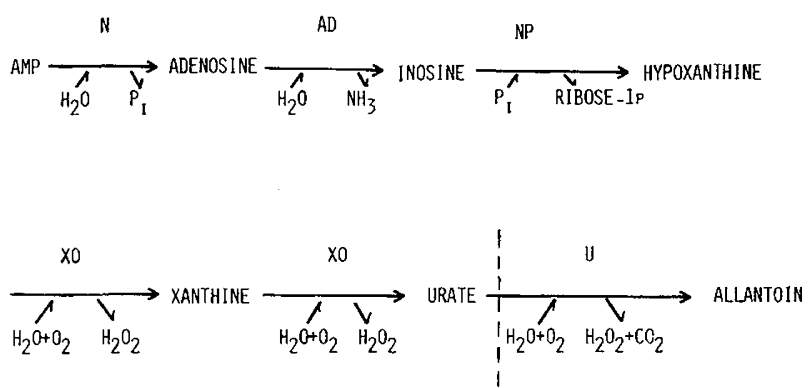

Fig. 1. Schematic representation of purine catabolism. $N$ : 5-nucleotidase; $A D$ : adenosine deaminase; $N P$ : nucleoside phosphorylase; $X O$ : xanthine oxidase; $U$ : uricase.

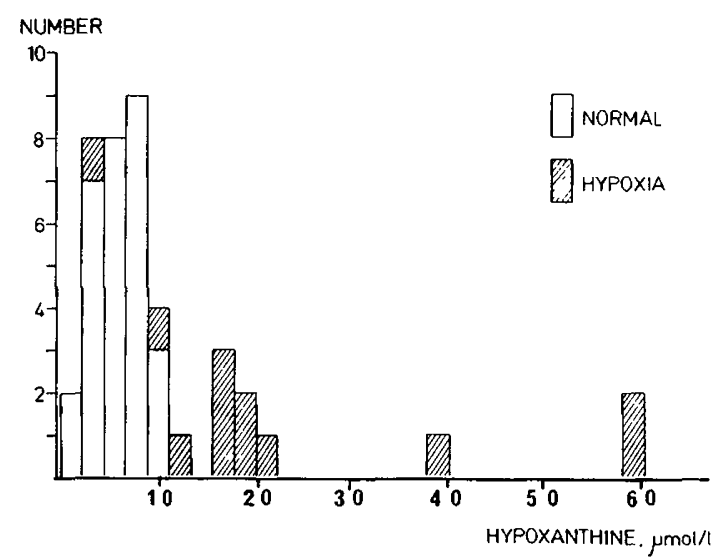

Fig. 2. The distribution of the hypoxanthine concentration of the umbilical cord plasma of 29 infants without clinical signs of intrauterine hypoxia, and 12 infants with clinical signs of intrauterine hypoxia.
$10 \mathrm{~min}$ before delivery when a period of bradycardia with a fetal heart rate of 80 beats/min was registered.

Table 1 gives the hypoxanthine levels together with the diagnostic criteria of the 12 infants. Although the material is too small to draw definite conclusions, it seems that serious hypoxia gives a considerable increase in the hypoxanthine level, whereas a moderate hypoxia gives a moderate increase. Both infants with hypoxanthine levels more than $60 \mu \mathrm{mol} / \mathrm{liter}$ died, and those with hypoxanthine ranging from $10-20$ $\mu \mathrm{mol} /$ liter had clinical signs of moderate hypoxia.

Figures 3 and 4 show the correlation between the $\mathrm{Pa}_{2}$ and the hypoxanthine concentration in two premature infants developing idiopathic respiratory distress. In Figure $3 \mathrm{PaO}_{2}$ was down to about $30 \mathrm{~mm} \mathrm{Hg}$ for several hours and the patient had to be treated with artificial ventilation. Hypoxanthine measurements after the termination of this treatment show increased values more than $24 \mathrm{hr}$ after this serious period of hypoxemia was ended.

In Figure 4 the hypoxanthine level was increased to 46.0 $\mu \mathrm{mol} /$ liter. The $\mathrm{Pa}_{\mathrm{O}_{2}}$ was very low and the patient died $4 \mathrm{hr}$ later. One hour before the patient died the hypoxanthine concentration was decreased to $10 \mu \mathrm{mol} / \mathrm{liter}$. Such a decrease has been observed also in other dying patients. The explanation of this phenomenon cannot yet be given.

Figure 5 shows the rate of the decrease of the metabolite in umbilical arterial plasma of three newborn infants with clinical signs of intrauterine hypoxia and elevated hypoxanthine levels.

Table 1. Hypoxanthine level of plasma of umbilical cord of 12 newborn infants with diagnosed intrauterine hypoxia

\begin{tabular}{cccl}
\hline Case & $\begin{array}{c}\text { Hypoxanthine, } \\
\mu \text { mol/liter }\end{array}$ & $\begin{array}{c}\text { Apgar score, } \\
1 \mathrm{~min}\end{array}$ & $\begin{array}{c}\text { Diagnosis of } \\
\text { intrauterine } \\
\text { hypoxia }\end{array}$ \\
\hline 1 & 19.0 & 6 & Apgar score \\
2 & 17.5 & 9 & Bradycardia \\
3 & 18.0 & 4 & Apgar score \\
4 & 17.0 & 9 & Bradycardia \\
5 & 60.5 & 2 & Apgar score \\
6 & 14.0 & 9 & Bradycardia \\
7 & 6.0 & 9 & Meconium-stained \\
& & & amniotic fluid \\
8 & 61.0 & 0 & Apgar score \\
9 & 10.5 & 9 & Bradycardia \\
10 & 41.0 & 3 & Apgar score \\
11 & 20.0 & 6 & Apgar score \\
12 & 19.5 & 9 & Bradycardia
\end{tabular}

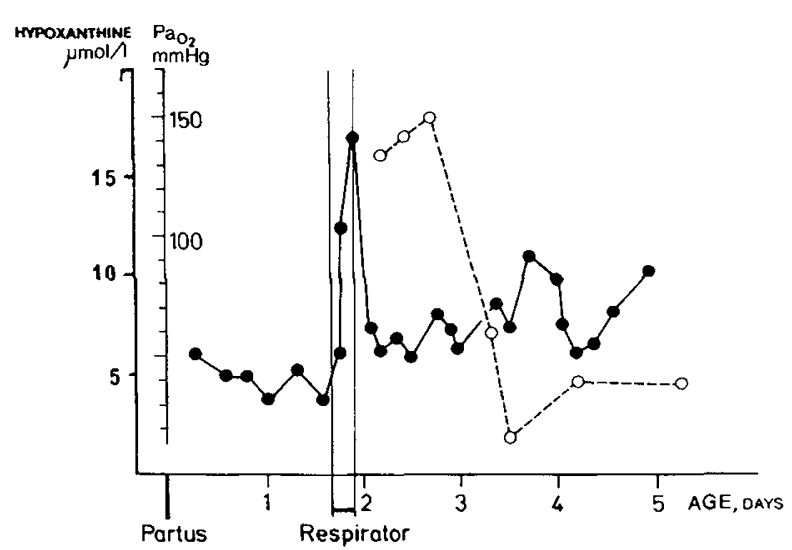

Fig. 3. The correlation between $\mathrm{PaO}_{2}(\bullet--\bullet)$ and the hypoxanthine $\left(\mathrm{O}_{-}-\mathrm{O}\right)$ level in umbilical artery plasma of a patient with ideopathic respiratory distress syndrome necessitating artificial ventilation. 


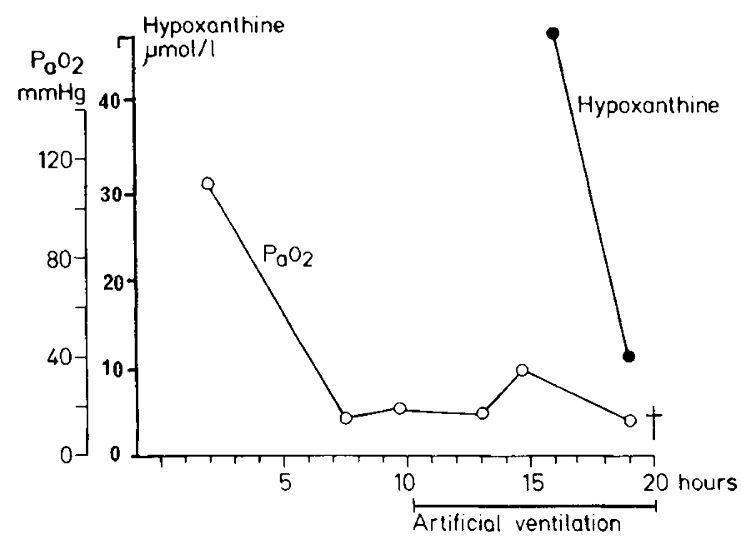

Fig. 4. The correlation between $\mathrm{Pa}_{2}$ and hypoxanthine in umbilical artery plasma of a patient with ideopathic respiratory distress syndrome. The patient died $19 \mathrm{hr}$ after birth.

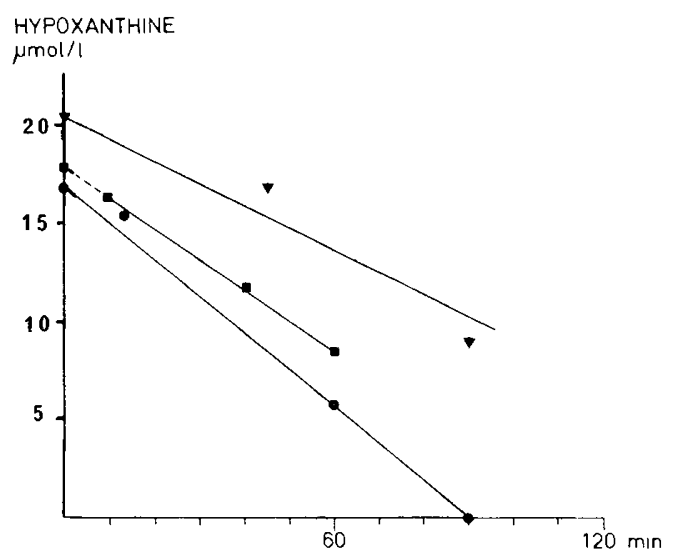

Fig. 5. The hypoxanthine level at birth in umbilical cord plasma and the hypoxanthine level of umbilical artery plasma the first hours of life in three patients with clinical signs of intrauterine hypoxia.

Measurements were done three to four times in the first $2 \mathrm{hr}$ after birth. These infants had no signs of postpartum hypoxia as measured by $\mathrm{Pa}_{\mathrm{O}_{2}}$ and acid-base measurements during the first $2 \mathrm{hr}$ of life. It seems that the decrease of the concentration of the metabolite in plasma is fairly constant at approximatelly $10 \mu \mathrm{mol} / \mathrm{liter} / \mathrm{hr}$.

\section{DISCUSSION}

The parameters available today in diagnosis of hypoxia are in many ways inadequate. $\mathrm{Pa}_{2}$, for instance, is not a measure of hypoxia, but hypoxemia. This parameter is quickly reversible, and depends mainly upon the function of the respiratory and circulatory systems.

Base deficit (BD) is a better measure of hypoxia. The BD is, however, also rapidly reversible, although not as fast as $\mathrm{Pa}_{\mathrm{O}_{2}}$. Treatment with $\mathrm{NaHCO}_{3}$ or Tris-buffer (THAM) will add to the difficulties in interpreting BD. Immature kidneys, especially in premature infants, often contribute to a metabolic acidosis, and for these and possibly other reasons $\mathrm{BD}$ may increase without existing hypoxia.

Evidence so far indicates that hypoxanthine is a sensitive parameter of hypoxia. Continuous monitoring of the fetal heart rate indicates that a short period of bradycardia might give a considerable increase in the hypoxanthine level. Hence it seems that only a few minutes of hypoxia is sufficient to give increased hypoxanthine concentration in plasma. If adequate oxygenation is established, the hypoxanthine level is slowly reverted to normal values. Therefore, hypoxanthine can be used to diagnose hypoxia retrospectively.
Table 2. Hypoxanthine values in umbilical cord plasma and base deficit (BD) and $\mathrm{pH}$ values in umbilical artery blood in four infants with diagnosed intrauterine hypoxia

\begin{tabular}{cccc}
\hline Case & $\begin{array}{c}\text { Hypoxanthine, } \\
\mu \text { mol/liter }\end{array}$ & $\begin{array}{c}\text { BD, } \\
\text { mmol/liter }\end{array}$ & $\mathrm{pH}$ \\
\hline 1 & 17.0 & 11.3 & 7.17 \\
2 & 19.5 & 6.5 & 7.25 \\
3 & 17.5 & 8.0 & 7.11 \\
4 & 18.0 & 9.8 & 7.34 \\
\hline
\end{tabular}

In the further investigation of this parameter it will be necessary to compare the hypoxanthine level in plasma with other well established parameters such as base deficit, standard bicarbonate, and $\mathrm{pH}$, and such a study is under way. So far BD and $\mathrm{pH}$ have been measured in umbilical cord artery blood at partus and compared with the hypoxanthine level in only four newborn infants with diagnosed intrauterine hypoxia. These values are given in Table 2 (18).

We are also planning animal experiments in order to evaluate the hypoxanthine test in hypoxia. One problem is, however, that the purine catabolism of the primates differs from other mammals.

As the hypoxanthine liberated from the tissue during hypoxia to a large extent will be eliminated by the kidneys, we also plan to study whether the urinary output of hypoxanthine may be used as a measure of the degree of hypoxia.

\section{SUMMARY}

The hypoxanthine concentration in the plasma of the newborn infant was measured with a $\mathrm{P}_{\mathrm{O}_{2}}$ electrode. During hypoxia this metabolite increased more than fivefold the normal level. The degree of increase seemed to be related to the degree of hypoxia.

The degradation of this purine metabolite was so slow that such an increase could be detected even a long time after the hypoxia was ended. This indicates the possibilities of a retrospective hypoxia diagnosis.

\section{REFERENCES AND NOTES}

1. Boda, D., Pénzes, P., Gecse, A., Streitman, K., Zsilinsky, E., and Karády, I.: Uric acid nephropathy in shocked rats after blocking of uricase activity with triazine compounds. Can. J. Physiol., Pharmacol., 51: 496 (1973).

2. Berne, R. M.: Cardiac nucleotides in hypoxia: Possible role in regulation of coronary blood flow. Amer. J. Physiol., 204: 317 (1963).

3. Booth, V. H.: The specificity of xanthine oxidase. Biochem. J., 32: 494 (1938).

4. Cantarow, A., and Schepartz, B.: Biochemistry, Ed. 4, p. 519 (Saunder:i, Philadelphia, 1967).

5. Cowsert, M. K., Jr., Carrier, O., Jr., and Crowell, J. W.: The effect of hemorrhagic shock on blood uric acid level. Can. J. Physiol., 44: 861 (1966).

6. Crowell, J. W., Jones, C. E., and Smith, E. E.: Effect of allopurinol on hemorrhagic shock. Amer. J. Physiol., 216: 744 (1969).

7. Gyuton, A. C.: Textbook of Medical Physiology, Ed. 4, p. 488 , (Saunders, Philadelphia, 1971).

8. Handbook of Chemistry and Physics, F-55, Ed. 52 (The Chemical Rubber Co., Cleveland, 1971-1972).

9. Kalckar, H. M.: Differential spectrophotometry of purine compounds by means of specific enzymes. J. Biol. Chem., 167: 429 (1947).

10. LePage, G. A.: Biological energy transformation during shock as shown by tissue analysis. Amer. J. Physiol., 146: 267 (1946).

11. Nichols, J., Miller, A. T., Jr., and Hiatt, E. P.: Influence of muscular exercise on uric acid excretion in man. J. Appl. Physiol., 3: 501 (1950).

12. Parnas, J. K.: Über die Ammoniakbildung im Muskel und Ihren Zusammenhang mit Funktion und Zustandsänderung. Biochem. Z., 206: 16 (1929).

13. Vasko, K. A., Dewall, R. A., and Riley, A. M.: Effect of allopurinol in renal ischemia. Surgery, 71: 787 (1972).

14. White, A., Handler, P., and Smith, E. L.: Principles of Biochemistry, Ed. 5, p. 835 (McGraw-Hill Book Co., New York, 1973). 
15. Örström, A., Örström, M., and Krebs, H. A.: The formation of hy poxanthine in pigeon liver. Biochem. J., 33: 990 (1939).

16. The full description of this method is in preparation.

17. Radiometer, Copenhagen.

18. Data reproduced by permission of Dr. L. E. Bratteby.

19. This work was supported by the University of Uppsala, and the Norweigian Research Council for the Science and Humanities.
20. This work was inspired by an idea of Professor C. H. DeVerdier and Professor G. Rooth, University Hospital, Uppsala, Sweden. I wish to express my gratitude to Professor G. Rooth for valuable support.

21. Requests for reprints should be addressed to: O. D. Saugstad, M.D., Institute for Surgical Research, Rikshospitalet, Oslo 1, Norway.

22. Accepted for publication November 15, 1974.
Alveoli

collateral ventilation

hemorrhagic atelectasis neonate

pulmonary system

\title{
A New Model for Neonatal Pulmonary Hemorrhage Research
}

\author{
ROBERT V. KOTAS, ${ }^{(27)}$ THOMAS J. WELLS, LEROY C. MIMS, ELIZABETH J. TRAINOR, \\ AND CARYL L. WILES
}

The William K. Warren Medical Research Center, Tulsa, Oklahoma, USA

\section{Extract}

Hemorrhagic atelectasis was successfully produced in newborn rabbits by pharmacologically narrowing airways leading to alveoli ventilated with oxygen-enriched gas. Between $48 \%$ and $62 \%$ of alveoli filled with blood cells. Areas of lung with a tendency to collapse were measured by pressure volume studies. Animals given supplemental oxygen retained $56 \%$ of total lung volume compared with $79 \%$ in the pilocarpine group, which suggested increased effectiveness of antiatelectasis factors in the latter. Less total lung gas was present in the pilocarpine group $(4.0 \pm 0.4 \mathrm{cc} / \mathrm{g})$ compared with oxygen controls $(5.1 \pm 0.81 \mathrm{cc} / \mathrm{g})$, which indicated more noninflatable lung. Neither surfactant deficiency nor heart failure needed to be present for pulmonary hemorrhage to occur.

\section{Speculation}

Neonates are at increased risk of pulmonary hemorrhagic atelectasis because of their incomplete pulmonary anatomic development, if their airways become obstructed while breathing high concentrations of oxygen.

Pulmonary hemorrhage in lungs of neonates at autopsy has been a common finding $(1,10,11)$. One recent report considered it to be the principle cause of death in $9 \%$ of autopsies reviewed in that study (11). Diagnosis during life has been a difficult matter. Prenatal complications, such as toxemia, abruptio, and prolapsed cord, have been seen frequently but none has been specifically related $(2,5$, 23). No single diagnostic laboratory test or X-ray pattern (23) has been reported. For the most part the infants have weighed less than $2,000 \mathrm{~g}$ but have been heavier than infants who subsequently develop respiratory distress syndrome $(6,10)$. The clinical diagnosis is only evident in a fraction of cases when frank airway bleeding accompanies sudden deterioration.
Some authors have suggested that pulmonary hemorrhage follows altered coagulation capacity resulting from the stress and acidosis of conditions such as hypothermia and the respiratory distress syndrome $(7,14,20)$. Rowe and Avery $(11,23)$ have suggested that pulmonary hemorrhage may specifically follow surfactant inactivation. Others have theorized that the hemorrhage occurs because of physical changes in the lung resulting from high concentrations of therapeutic oxygen and/or left heart failure $(6,24)$.

Structural inadequacies might make neonatal lungs especially susceptible to pulmonary hemorrhage. Neonatal small airways are disproportionately long for their diameter and may close during tidal breathing $(15,18,19)$. Peripheral airway conductance is quite low until about 5 years of age (15) and infants and children have absent or poorly developed collateral ventilation $(15,18)$. The term collateral ventilation describes air which passes from alveolus to alveolus without traveling along the airways.

Recently, an analysis of pulmonary interdependence suggested that the lack of adequate collateral ventilation puts infants at special risk of developing hemorrhagic atelectasis (21). Mead et al. (21) have theorized that if neonatal airways become obstructed while alveoli are filled with a rapidly assimilated gas such as oxygen, local alveolar pressures could fall to levels which would result in capillary rupture because of lack of pressure relief mechanisms.

We tested this hypothesis in neonatal rabbits by pharmacologically narrowing airways leading to alveoli ventilated with oxygen-enriched gas and successfully produced hemorrhagic atelectasis.

\section{METHODS}

Females from a purebred strain of New Zealand White rabbits who had successfully completed at least three prior pregnancies were mated with a single buck under direct observation. The pregnancies were carried to term and the 